\title{
Preparation of Polyimide/Zinc Oxide Nanocomposite Films via an Ion-Exchange Technique and Their Photoluminescence Properties
}

\author{
Shuxiang Mu, ${ }^{1,2}$ Dezhen Wu, ${ }^{1}$ Shengli Qi, ${ }^{1}$ and Zhanpeng $W^{1}$ \\ ${ }^{1}$ State Key Laboratory of Chemical Resource Engineering, Beijing University of Chemical Technology, Beijing 100029, China \\ ${ }^{2}$ Research and Development Department, Sinomatech Wind Power Blade Co., Ltd, Beijing 102101, China
}

Correspondence should be addressed to Zhanpeng Wu, wuzp@mail.buct.edu.cn

Received 14 November 2010; Accepted 9 February 2011

Academic Editor: Xuedong Bai

Copyright (c) 2011 Shuxiang Mu et al. This is an open access article distributed under the Creative Commons Attribution License, which permits unrestricted use, distribution, and reproduction in any medium, provided the original work is properly cited.

Polyimide (PI) composite films with $\mathrm{ZnO}$ nanoparticles embedded in the surface layer were prepared by alkali hydrolyzation following ion exchange in $\mathrm{Zn}\left(\mathrm{NO}_{3}\right)_{2}$ solution and thermal treatment of the zinc ion-doped PI films in air atmosphere. The effect of alkali treatment, ion exchange, and thermal treatment conditions was investigated in relation to the amount of zinc atomic loading, morphology, photoluminescence (PL), and thermal properties of the PI/ZnO composite films using ICP, XPS, FE-SEM, TEM, Raman microscope, TGA, and DSC. ZnO nanoparticles were formed slowly and dispersed uniformly in the surface-modified layers of PI films with an average diameter of $20 \mathrm{~nm}$. The PL spectra of all the PI/ZnO nanocomposite films obtained at $350^{\circ} \mathrm{C} / 7 \mathrm{~h}$ possessed a weak ultraviolet emission peak and a broad and strong visible emission band. The PI/ZnO nanocomposite films maintained the excellent thermal property of the host PI films.

\section{Introduction}

Nanoparticles and/or nanocrystals of metal oxide semiconductor material have been extensively studied in the past decade due to their unique properties and wide application in diverse areas. Many research groups have focused on dispersing metal oxide nanoparticles into polymer matrix, as the hybrid nanocomposites not only inherit the functionalities of semiconductor nanoparticles but also possess advantages of polymers such as flexibility, film integrity, and conformity. Among metal oxide materials, $\mathrm{ZnO}$ is a multifunctional n-type semiconductor with prominent physical and chemical properties such as wide band gap $(3.4 \mathrm{eV})$, large exciton binding energy ( $60 \mathrm{meV})$, good chemical stability, and low dielectric constant. It is of particular interest in many applications including antireflection coating, transparent electrodes in solar cells, gas sensors, ultraviolet light-emitting diodes, piezoelectric devices, and surface acoustic wave devices [1-5]. Combining $\mathrm{ZnO}$ nanoparticles with a polymer should enhance their optical properties such as fluorescence, transparence and radiation durability. The polymer/ZnO composites have been produced with many different matrices such as poly (vinylpyrrolidone) [6], poly(methyl methacrylate) [7], poly (hydroxyethyl methacrylate) [8], poly (ethylene glycol) [9], low density polyethylene [10], poly(ethylene oxide) [11], Nylone-6 [12], polyurethane [13], and polyimide (PI) [14-23]. Among the various polymers, PI is a promising matrix which has attracted a lot of interest for photonic applications because of its conjugate $\pi$-electron system. Moreover, PI possesses excellent dielectric properties, outstanding thermal and chemical stability, and low coefficients of thermal expansion [24-26]. These attributes make the $\mathrm{PI} / \mathrm{ZnO}$ composites have potential applications in optoelectronics, light-emitting diodes, photonics, and flatpanel display industries.

The most widely used method to prepare the $\mathrm{ZnO}$ nanoparticles dispersed in polymer matrix is directly incorporating $\mathrm{ZnO}$ nanoparticles or zinc salts or complex into polymer precursor solution via bulk polymerization of monomers and then thermal curing of the composites [6-13, 20$22]$. However, these processes often lead to inhomogeneous agglomeration of the $\mathrm{ZnO}$ nanoparticles in polymer matrix. 


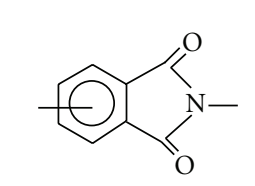

Bare PI

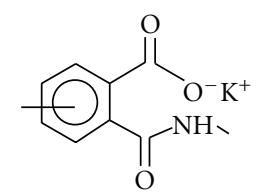

Surface-modified PI

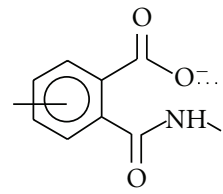

$\mathrm{Zn}^{2+}$-doped PI

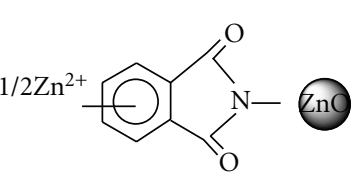

ZnO-incorporated PI

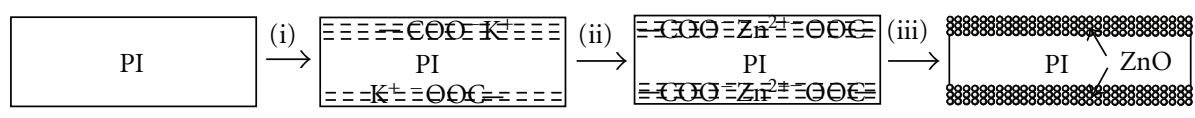

FIGURE 1: Schematic illustration of the preparation process for PI/ZnO films: (i) surface modification of PI films in aqueous KOH solution, (ii) incorporation of zinc ions via an ion-exchange reaction, and (iii) thermal-treatment-induced reimidization and formation of $\mathrm{ZnO}$.

To obtain a sharp size distribution, $\mathrm{ZnO}$ nanoparticles need to be modified by surfactant or polymer, making these processes very complex. Kim and co-workers [22, 23] developed a new method to fabricate $\mathrm{ZnO}$ nanoparticles in very thin PI film by spin-coating the PI precursor, poly (amic acid) (PAA), on thin $\mathrm{Zn}$ metal film and then thermal-treating the hybrids during which $\mathrm{Zn}$ thin film reacted with PAA to form $\mathrm{ZnO}$ nanoparticles which were distributed within the PI thin layer. However, the size and distribution of the $\mathrm{ZnO}$ nanoparticles and the composite film thickness are difficult to control.

Recently, several groups [24-28], including ours [24, 25], developed an ion-exchange technique to prepare metal particles embedded in polyimide film. This technique utilizes a simple alkali treatment-based surface modification of the PI film to form carboxylic acid groups in the modified layer through imide ring-cleavage reactions, as well as incorporation of metal ions to form metal salts of PAA via ion-exchange reactions in metal salt solution. Final thermal, hydrogen, or reductant-induced reduction of metal ions leads to the formation of metal nanoparticles embedded in PI film surface layers. This method allows control of the morphologies and properties of the composite films by adjusting the initial alkali treatment (time, concentration, and temperature), subsequent ion-exchange conditions (time, concentration, and temperature), and final reduction conditions. This ion-exchange technique could be extended to synthesizing transitional metal oxide nanoparticles dispersed in PI film surface layers when the thermal treatment process of transitional metal ion-doped precursor film is conducted in air atmosphere. Very recently, based on the ion-exchange technique, we reported the $\mathrm{Co}_{3} \mathrm{O}_{4}$ metal oxide layers to a flexible PI substrate. Such technique resulted in $\mathrm{Co}_{3} \mathrm{O}_{4}$ layers with $\mathrm{Co}_{3} \mathrm{O}_{4}$ average diameter of $15 \sim 45 \mathrm{~nm}$ formed on both surfaces of the PI films [29]. In this study, due to $\mathrm{ZnO}$ endowed with above-mentioned many potential applications, we extend this technique to fabricating $\mathrm{PI} / \mathrm{ZnO}$ films. Different content of $\mathrm{ZnO}$ nanoparticles embedded $\mathrm{PI} / \mathrm{ZnO}$ films was prepared via the ion-exchange technique. The variation in surface morphologies and photoluminescence (PL) properties of the resulted composite films during thermal treatment was investigated. In addition, the effect of initial zinc ion loading on the morphologies, PL properties, and thermal properties of the final composite films were also studied.

\section{Experimental}

2.1. Materials. Pyromelltic dianhydrides oxydianiline(PMDAODA)-based polyimide films with thickness of $50 \mu \mathrm{m}$ were obtained from Liyang Huajing Electronic Material Co., Ltd., Jiangsu province (China). The PI films were rinsed by ultrasonic cleaning for $10 \mathrm{~min}$ in deionized water and dried in ambient environment prior to use. Zinc nitrate hexahydrate $\left(\mathrm{Zn}\left(\mathrm{NO}_{3}\right)_{2} \cdot 6 \mathrm{H}_{2} \mathrm{O}, \geq 99 \%\right)$ was purchased from Sinopharm Chemical Reagent Co., Ltd (China). Potassium hydroxide $(\mathrm{KOH})$ was obtained from Beijing Chemicals Works. All chemicals were analytical grade and used without further purification.

2.2. Preparation of $P I / Z n O$ Nanocomposite Films. The procedures for preparing $\mathrm{PI} / \mathrm{ZnO}$ nanocomposite films are illustrated in Figure 1. First, PI films were treated by $5 \mathrm{M}$ aqueous $\mathrm{KOH}$ solution at $50^{\circ} \mathrm{C}$ for several minutes to hydrolyze the film surfaces. After removal from the base, they were rinsed with copious amount of deionized water and were then blown dry with air. Then, the surface-modified PI films were immersed into aqueous $\mathrm{Zn}\left(\mathrm{NO}_{3}\right)_{2}$ solution at room temperature for certain time to incorporate zinc ions into the films through an ion-exchange reaction between potassium and zinc ions. After ion exchange, the films were rinsed by deionized water to remove the surface residual $\mathrm{Zn}\left(\mathrm{NO}_{3}\right)_{2}$ solution and dried in ambient atmosphere. Finally, the precursor films were reimidized by slowly heating to $350^{\circ} \mathrm{C}$ within $3 \mathrm{~h}$ in a forced air oven and were kept at $350^{\circ} \mathrm{C}$ for several hours. The alkali treatment time, concentration of aqueous $\mathrm{Zn}\left(\mathrm{NO}_{3}\right)_{2}$ solution, and ion-exchange time are listed in Table 1 .

2.3. Characterization. The amount of potassium and zinc ions incorporated into the PI films was estimated by a Seiko Instruments SPS 8000 inductively coupled plasma (ICP) atomic emission spectrometer. The doped potassium and zinc ions in the films were extracted by immersing the films into a dilute ( $5 \mathrm{vol} \%)$ aqueous nitric acid solution.

The X-ray photoelectron spectra (XPS) were recorded on an ESCALAB 250 spectrometer (Thermo Electron), using Al $\mathrm{K} \alpha \mathrm{X}$-ray as the excitation source. The spectra were collected at a takeoff angle of $45^{\circ}$. The pressure in the analysis chamber was maintained at $2 \times 10^{-10}$ mbar or lower during each measurement. To compensate for surface charging effects, all 
TABLe 1: Potassium and zinc ions loadings in the PI films after $\mathrm{KOH}$ hydrolysis and ion exchange in aqueous $\mathrm{Zn}\left(\mathrm{NO}_{3}\right)_{2}$ solution.

\begin{tabular}{|c|c|c|c|c|c|}
\hline $\begin{array}{l}\text { Sample } \\
\text { number }\end{array}$ & $\begin{array}{l}\mathrm{KOH} \text { treatment } \\
\text { time }(\mathrm{min})\end{array}$ & $\begin{array}{c}\mathrm{Zn}\left(\mathrm{NO}_{3}\right)_{2} \text { concentration } \\
(\mathrm{mol} / \mathrm{l})\end{array}$ & $\begin{array}{l}\text { Ion-exchange } \\
\text { time (min) }\end{array}$ & $\begin{array}{l}\mathrm{K}^{+} \text {loadings } \\
\left(\mathrm{nmol} / \mathrm{cm}^{2}\right)\end{array}$ & $\begin{array}{c}\mathrm{Zn}^{2+} \text { loadings } \\
\left(\mathrm{nmol} / \mathrm{cm}^{2}\right)\end{array}$ \\
\hline 1 & 5 & - & - & 1961 & 0 \\
\hline 2 & 5 & 0.01 & 5 & 951 & 465 \\
\hline 3 & 5 & 0.05 & 5 & 567 & 611 \\
\hline 4 & 5 & 0.20 & 5 & 479 & 702 \\
\hline 5 & 5 & 0.40 & 5 & 351 & 803 \\
\hline 6 & 30 & - & - & 10067 & 0 \\
\hline 7 & 30 & 0.40 & 60 & 585 & 3960 \\
\hline
\end{tabular}

binding energies (BEs) were referenced to the $\mathrm{C}$ 1s hydrocarbon peak at $284.6 \mathrm{eV}$. In peak synthesis, the full width at half maximum (FWHM) of Gaussian peaks was maintained constant for all components in a particular spectrum.

Surface morphologies were observed using a fieldemission scanning electron microscope (FE-SEM) (SEM4700 , Hitachi) at an accelerating voltage of $20 \mathrm{kV}$ after samples were coated with ca. $5 \mathrm{~nm}$ of palladium-gold alloy. The cross-sectional morphologies of the films were investigated by transmission electron microscopy (TEM, Hitachi H-800) operating at $200 \mathrm{kV}$. The samples were cut perpendicular to the film surface using an ultramicrotome. Then, the thin sections floating on a water bath were mounted onto the carbon-coated TEM copper grids for analysis.

The room temperature photoluminescence spectra were obtained on a Renishaw RM-1000 Confocal Raman microscope using $325 \mathrm{~nm}$ (He-Cd laser source) as the excitation wavelength.

Thermogravimetric analysis (TGA) and differential scanning calorimetry (DSC) analysis were performed using a thermal analyses system (NETZSCH STAR 449C) at a heating rate of $10^{\circ} \mathrm{C} / \mathrm{min}$.

\section{Results and Discussion}

3.1. Consideration and Characterization of the Zinc IonDoped Precursor Films. Many investigations reported in the literature have defined the chemical mechanism of polyimide surface reactions when polyimide is modified by aqueous alkaline solution, which consists in the hydrolytic cleavage of the imide groups contained in the repeating unit to form potassium (or sodium) salts of carboxyl acid groups and amide bonds [26-28]. The zinc ions $\left(\mathrm{Zn}^{2+}\right)$ can be incorporated via subsequent ion-exchange process by immersing the surface-modified films into aqueous $\mathrm{Zn}\left(\mathrm{NO}_{3}\right)_{2}$ solution to form poly (amic acid) zinc salt. Table 1 shows the potassium and zinc ion loadings per unit area of the PI films under various alkali treatment and ion-exchange conditions. When the PI films were hydrolyzed in $5 \mathrm{M}$ aqueous $\mathrm{KOH}$ solution at $50^{\circ} \mathrm{C}$ for $5 \mathrm{~min}$ and ion-exchanged in aqueous $\mathrm{Zn}\left(\mathrm{NO}_{3}\right)_{2}$ solution at room temperature for $5 \mathrm{~min}$, the zinc ion loadings increased from $465 \mathrm{nmol} / \mathrm{cm}^{2}$ to $803 \mathrm{nmol} / \mathrm{cm}^{2}$ with increasing the concentration of aqueous $\mathrm{Zn}\left(\mathrm{NO}_{3}\right)_{2}$ solution from $0.01 \mathrm{M}$ to $0.40 \mathrm{M}$. When the PI film was hydrolyzed in $5 \mathrm{M}$ aqueous $\mathrm{KOH}$ solution at $50^{\circ} \mathrm{C}$ for $30 \mathrm{~min}$ and ion-exchanged in $0.40 \mathrm{M}$ aqueous $\mathrm{Zn}\left(\mathrm{NO}_{3}\right)_{2}$ solution at room temperature for $60 \mathrm{~min}$, the zinc ion loading was increased to $3960 \mathrm{nmol} / \mathrm{cm}^{2}$. Theoretically, zinc ions are stoichiometrically incorporated into the modified layer through an ion-exchange reaction with potassium ions in a 1:2 molar ratio. The metal ion loading is affected by many different factors such as the thickness of modified layer $[26,28]$ and ion-exchange conditions (temperature, time, and concentration). Therefore, the total number of loaded zinc ions could be controlled by simply varying the initial modified layer thickness of PI film or by varying the concentration of zinc salt solution while maintaining the ionexchange time in very short time. Ikeda et al. $[26,28]$ have reported that when the PI films were surface-treated in $5 \mathrm{M}$ aqueous $\mathrm{KOH}$ solution at $50^{\circ} \mathrm{C}$ for $5 \mathrm{~min}$ and ion-exchanged in $0.05 \mathrm{M} \mathrm{CuSO}_{4}$ solution at room temperature for $5 \mathrm{~min}$, potassium ions in modified layer could be completely replaced by copper ions. However, our results show that about $29 \%$ of potassium ions were remained in the PI films under the same alkali hydrolyzation and ion-exchange conditions. Even for the film that was ion exchanged in $0.40 \mathrm{M}$ aqueous $\mathrm{Zn}\left(\mathrm{NO}_{3}\right)_{2}$ solution for $60 \mathrm{~min}$, about $6 \%$ potassium ions were remained. These results indicate that the ion-exchange reaction between potassium and zinc ions may be a relatively slow process compared with that between potassium and other metal ions such as copper ions.

3.2. Formation of the PI/ZnO Composite Films. Figure 2 shows the color changes of PI film during the whole preparation process. The bare PI film exhibits light yellow color (Figure 2(a)). After alkali treatment and following ion exchange in $\mathrm{Zn}\left(\mathrm{NO}_{3}\right)_{2}$ solution, only slight difference in film color was observed compared with that of the bare PI film (Figures 2(b) and 2(c)). However, the film color changed dramatically upon treatment temperature and time during thermal-treating the zinc ion-doped PI film in air atmosphere. Typically, in the initial $3 \mathrm{~h}$ heating process, the film color gradually became darker with increasing thermal treatment temperature. When the temperature reached $350^{\circ} \mathrm{C}$, the PI film displayed dark brown color as seen in Figure 2(d). Further extending thermal treatment time at $350^{\circ} \mathrm{C}$, the film color gradually returned to light yellow again. We ascribe the PI film color evolution during 


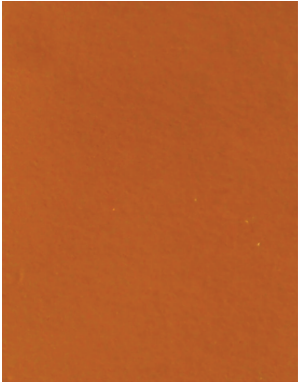

(a)

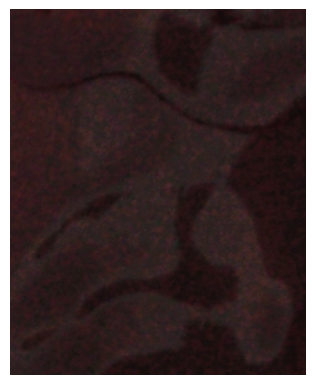

(f)

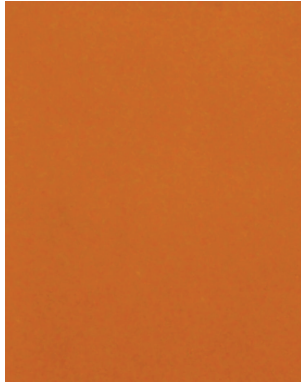

(b)

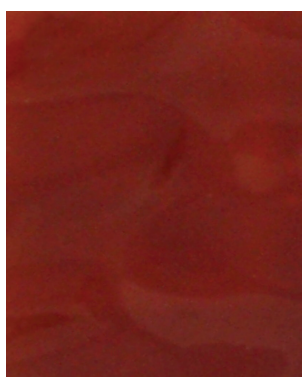

(g)

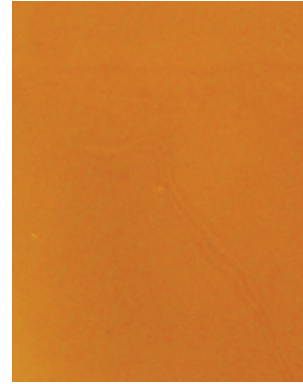

(c)

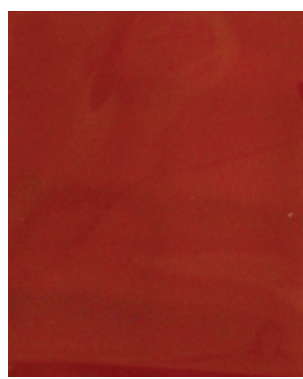

(h)

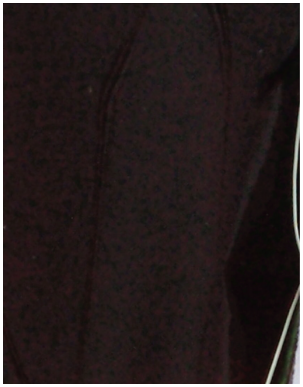

(d)

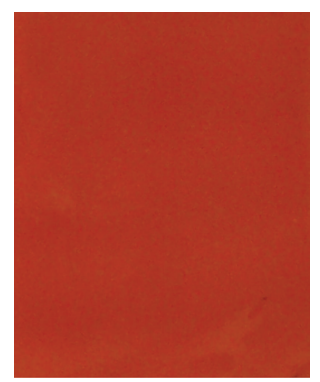

(i)

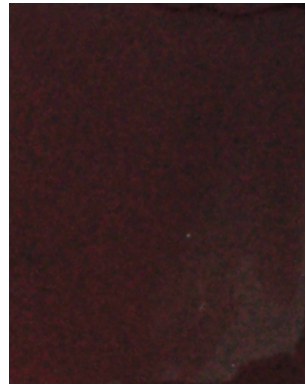

(e)

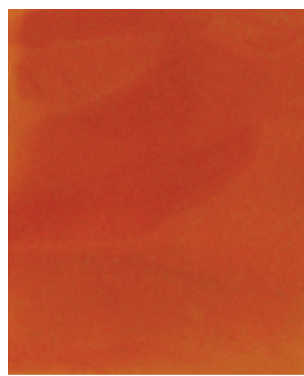

(j)

Figure 2: Photograph of (a) the bare PI film, (b) the KOH hydrolyzed film, (c) the $\mathrm{Zn}^{2+}$-doped film and the PI composite films obtained at $350^{\circ} \mathrm{C}$ for (d) 0, (e) 1, (f) 2, (g) 3, (h) 4, (i) 5, and (j) $7 \mathrm{~h}$.

thermal treatment to the following two possible reasons. First, $\mathrm{ZnO}$ particles generally show white appearance. But when the $\mathrm{ZnO}$ nanoparticles are in very small size, they may present different colors as it has been recognized that the color of inorganic nanoparticles depends much on the size, shape and the refractive index of the particles, and the mass concentration of particle material $[30,31]$. The $\mathrm{ZnO}$ nanoparticles may have already been formed in the surface-modified layers of PI film when temperature reached $350^{\circ} \mathrm{C}$. Owing to the very small size, these newly formed $\mathrm{ZnO}$ nanoparticles make the film exhibit dark brown color. Further prolonging the thermal treatment time at $350^{\circ} \mathrm{C}$, the small $\mathrm{ZnO}$ nanoparticles gradually grow larger or aggregate together, leading to the fading of dark brown color of the PI film. Besides, the $\mathrm{ZnO}$ nanoparticles in the surface layers of PI film may catalyst the degradation of surrounding PAA or PI during thermal treatment. The metal oxidecatalyzed oxidative degradation of PI has been observed in many studies on PI nanocomposites containing metal oxides such as iron oxide, cobalt oxide, titania, and zinc oxide $[20,29,32,33]$, which resulted in decrease of thermal stability of the hybrid films. Due to the nanosize effect, the newly formed $\mathrm{ZnO}$ nanoparticles have stronger catalytic activity. The decomposition products of PAA or PI such as the residual carbon on the film surface would make the film exhibit dark color. With extending thermal treatment time at high temperature, $\mathrm{ZnO}$ nanoparticles grow larger and their catalyst effect was greatly weakened. In the meantime, the residual decomposition products of PAA or PI on the film surface formed on the initial thermal treatment stages were gradually volatized. Therefore, the film color slowly returned to yellow again.

Figure 3 shows SEM images of the zinc ion-doped PI films thermally treated at $350^{\circ} \mathrm{C}$ for different hours. As can be observed, no particles could be detected on the PI films surface even after $3 \mathrm{~h}$ thermal treatment time at $350^{\circ} \mathrm{C}$. It is believed that the formed $\mathrm{ZnO}$ nanoparticles are too small to be detected, and most of them are embedded in the matrix of the surface-modified layer of PI film. As the treatment time at $350^{\circ} \mathrm{C}$ was increased to $5 \mathrm{~h}$, very small nanoparticles or clusters were observed on the PI film surface along with the fading of dark brown color to bright. Further extending thermal treatment time at $350^{\circ} \mathrm{C}$ to $7 \mathrm{~h}$, the small clusters grew to larger nanoparticles (about $15 \mathrm{~nm}$ ) which uniformly aggregate on the PI film surface. The surface atomic concentration of the zinc ion-doped PI films before and after thermal treatment at $350^{\circ} \mathrm{C}$ for $7 \mathrm{~h}$ extracted from the XPS measurement is listed in Table 2. The surface zinc concentration of the PI films before thermal treatment was only 2.2 at $\%$. However, it increased to 13.2 at $\%$ after thermal treatment, while the carbon concentration decreased about $28 \%$. Therefore, the zinc concentration increase was due to the relatively large amount of weight loss of carbon as a form of $\mathrm{CO}$ and $\mathrm{CO}_{2}$ gas during long period of thermal treatment at $350^{\circ} \mathrm{C}[33,34]$. The color evolvements and surface morphology changes of the PI composite films during thermal treatment indicate that the growth and aggregation of $\mathrm{ZnO}$ nanoparticles is a relatively slower process. 


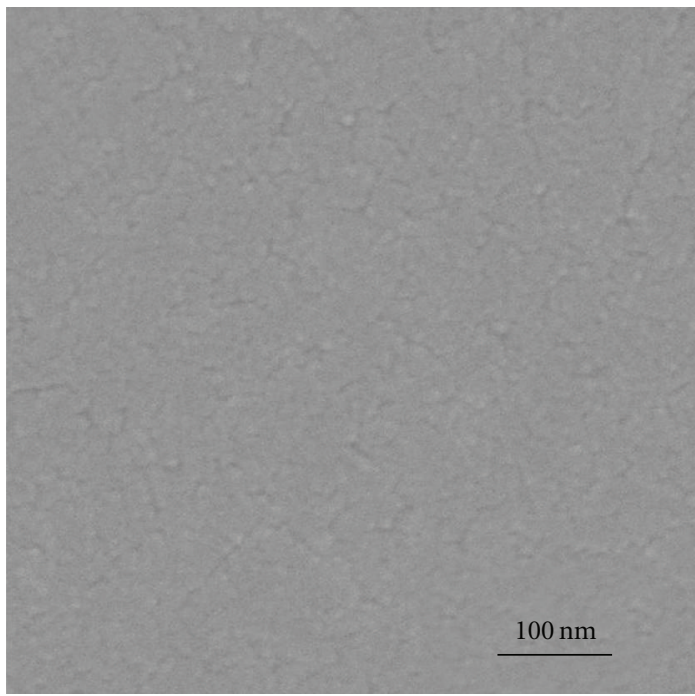

(a)

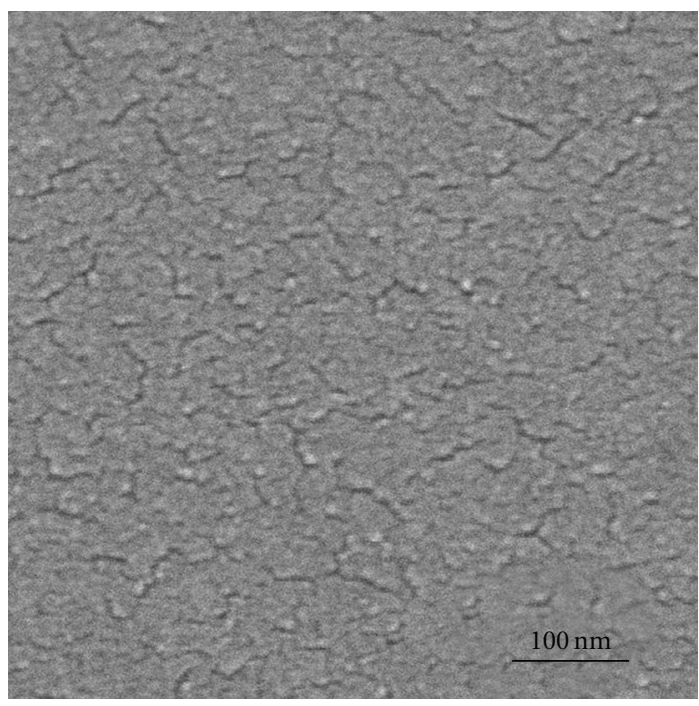

(c)

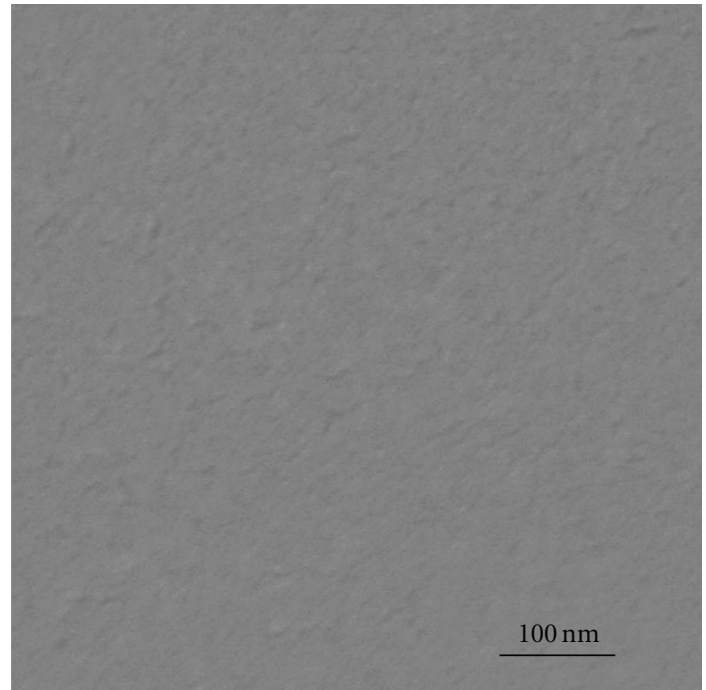

(b)

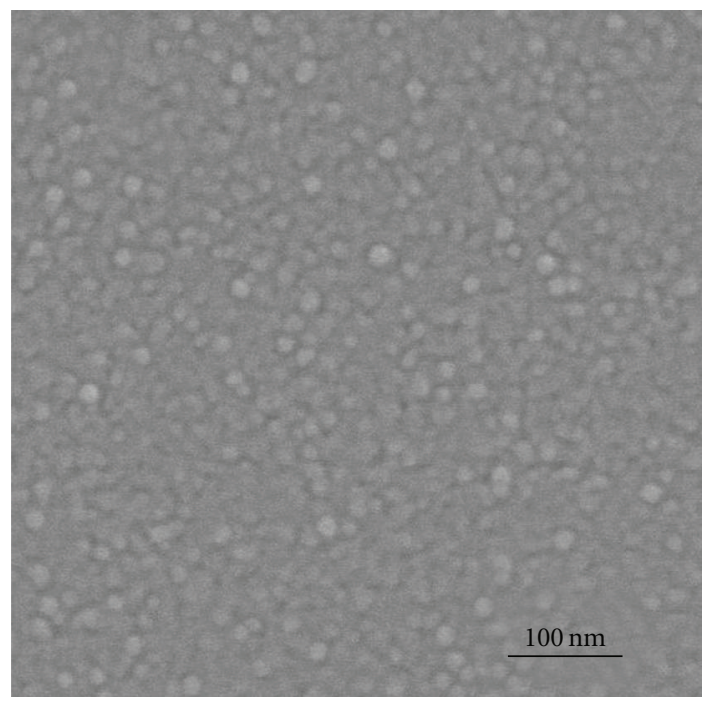

(d)

FIGURE 3: SEM images of the $\mathrm{Zn}^{2+}$-doped PI films after thermal treatment at $350^{\circ} \mathrm{C}$ for (a) 0, (b) 3, (c) 5 , and (d) $7 \mathrm{~h}$, respectively.

TABLE 2: Surface atomic concentration of the $\mathrm{Zn}^{2+}$-doped PI precursor film and the $\mathrm{PI} / \mathrm{ZnO}$ film obtained at $350^{\circ} \mathrm{C} / 7 \mathrm{~h}$ with initial zinc ion loadings of $803 \mathrm{nmol} / \mathrm{cm}^{2}$.

\begin{tabular}{lcccc}
\hline \multirow{2}{*}{ Samples } & \multicolumn{4}{c}{ Surface atomic concentration $(\%)$} \\
& $\mathrm{C}$ & $\mathrm{O}$ & $\mathrm{N}$ & $\mathrm{Zn}$ \\
\hline $\mathrm{Zn}^{2+}$-doped film & 69.7 & 21.6 & 6.5 & 2.2 \\
$\mathrm{PI} / \mathrm{ZnO}$ film & 50.1 & 32.7 & 4.0 & 13.2 \\
\hline
\end{tabular}

Figure 4 depicts the XPS spectra for the $\mathrm{Zn} 2 \mathrm{p}$ and $\mathrm{O}$ 1s core levels of the zinc ion-doped PI film and that thermally treated at $350^{\circ} \mathrm{C}$ for $7 \mathrm{~h}$. For the zinc ion-doped PI film, the $\mathrm{Zn} 2 \mathrm{p}$ XPS spectrum consists of the main $2 \mathrm{p}_{3 / 2}$ and $2 \mathrm{p}_{1 / 2}$ spin-orbit components at 1022.3 and $1045.5 \mathrm{eV}$, respectively. The $\mathrm{O}$ 1s core level of the zinc ion-doped PI film can be curve-fitted with two peak components, having BEs at $533.05 \mathrm{eV}$ for the ether species and $531.8 \mathrm{eV}$ for the carboxyl species $[35,36]$. Thermal treatment of the zinc ion-doped PI film in ambient atmosphere resulted in the formation of one additional oxygen species at the BE of $530.5 \mathrm{eV}$. This peak component was attributable to the $\mathrm{Zn}$ $\mathrm{O}$ species in zinc oxide [1]. The $\mathrm{Zn} 2 \mathrm{p}$ spectrum also consists of the main $2 \mathrm{p}_{3 / 2}$ and $2 \mathrm{p}_{1 / 2}$ spin-orbit components at 1022.2 and $1045.2 \mathrm{eV}$, respectively. These features are identical to those already reported for related $\mathrm{ZnO}$ systems [1]. Thus, by comparing the $\mathrm{Zn} 2 \mathrm{p}$ and $\mathrm{O}$ 1s XPS core level spectra of the zinc ion-doped PI films before and after thermal treatment, it can be concluded that $\mathrm{ZnO}$ was formed on the PI films surface after thermal treatment at $350^{\circ} \mathrm{C}$ for $7 \mathrm{~h}$. The attenuated total reflection-Fourier transform infrared (ATRFTIR) spectrum of the film obtained by heat treatment of the 


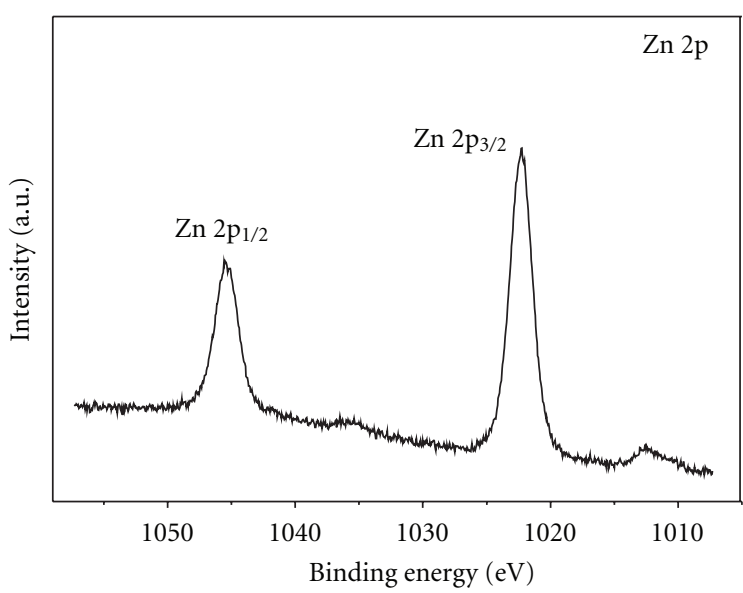

(a)

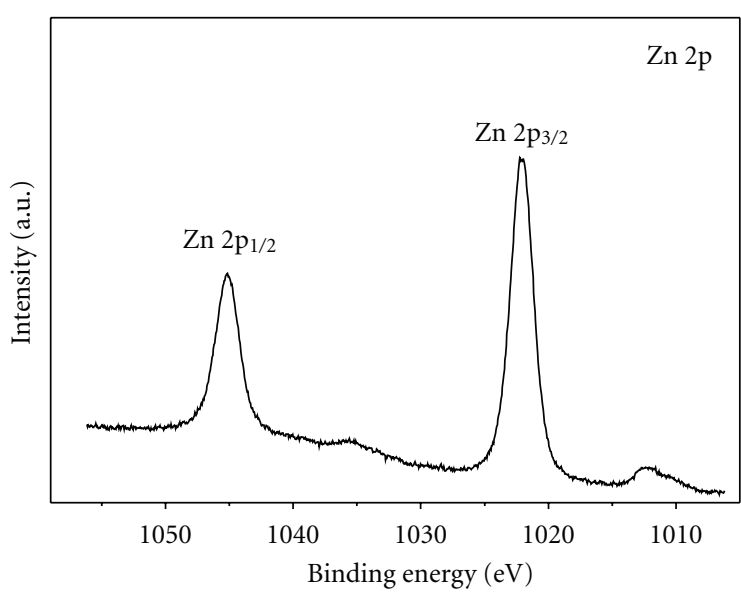

(c)

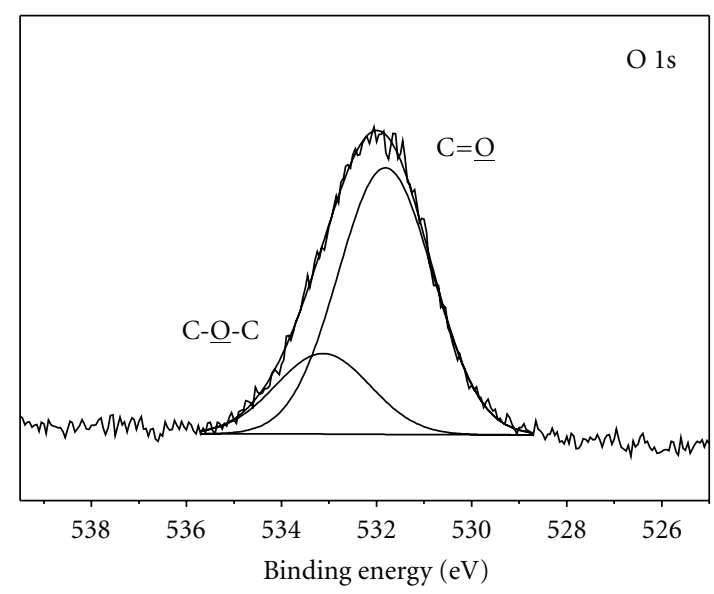

(b)

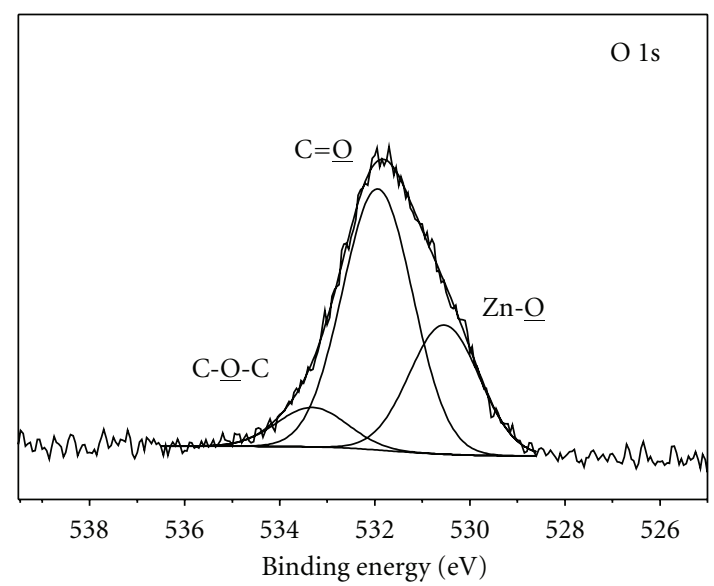

(d)

FIgURE 4: XPS spectra for the $\mathrm{Zn} 2 \mathrm{p}$ and $\mathrm{O}$ 1s core levels of $(\mathrm{a}, \mathrm{b})$ the $\mathrm{Zn}^{2+}$-doped film and (c, d) the PI composite film after thermal treatment at $350^{\circ} \mathrm{C}$ for $7 \mathrm{~h}$.

zinc ion-exchanged sample in ambient air is very similar to that of the bare PI film (the results were not shown here), indicating complete reimidization of the modified layer due to the elimination of water molecules from carboxyl groups and amide bonds to form heterocyclic imide rings.

Figure 5 shows the TEM images of the PI/ZnO nanocomposite films with different initial zinc ion loadings in the same alkali-treated layers. As all the PI films in Figure 5 were hydrolyzed in $5 \mathrm{M}$ aqueous $\mathrm{KOH}$ solution for $5 \mathrm{~min}$ at $50^{\circ} \mathrm{C}$, all the modified layer thicknesses of the PI films should be the same. However, after zinc ion incorporation and thermal treatment at $350^{\circ} \mathrm{C}$ for $7 \mathrm{~h}$, the surface composite layer of the films decreased from $700 \mathrm{~nm}$ to $90 \mathrm{~nm}$ in thickness with increasing the initial zinc ion loadings from 465 to $803 \mathrm{nmol} / \mathrm{cm}^{2}$. It is believed that the thickness decrease was due to the weight loss of carbon during thermal treatment in air, and the TGA-DSC results of the zinc ion-doped PI film can account for this.

Figure 6 shows the DSC and TGA curves of the zinc iondoped $\left(3960 \mathrm{nmol} / \mathrm{cm}^{2}\right)$ PI film obtained in air atmosphere and argon atmosphere. In argon atmosphere, there was no pronounced thermal effect in DSC curve, and the weight loss of the film was very slowly progressed until $570^{\circ} \mathrm{C}$, rapidly progressed between 570 and $650^{\circ} \mathrm{C}$, then became plateau until $800^{\circ} \mathrm{C}$, showing weight loss of only $40 \%$. On the other hand, in air atmosphere, two exothermic peaks appear in the temperature ranges of $330 \sim 500^{\circ} \mathrm{C}$ and 520 $700^{\circ} \mathrm{C}$ for the zinc ion-doped PI film (Figure 6(a)-1). The exothermic peak at $330 \sim 500^{\circ} \mathrm{C}$ with a weight loss of about $10 \%$ is suggested to arise from the oxidative decomposition of carbon in the film catalyzed by the newly formed $\mathrm{ZnO}$ nanoparticles. During the formation of $\mathrm{ZnO}$ nanoparticles in the surface layer, the weight loss of film was accelerated due to the catalytic effect on the oxidative decomposition of carbon. As increasing the zinc ion loading, considerable amount of catalytic sites increased and resulted in more active degradation of surrounding PI film. During the time, the unstable $\mathrm{ZnO}$ nanoparticles with high surface free energy are readily to aggregate together. Thus, the surface composite layer of the final obtained $\mathrm{PI} / \mathrm{ZnO}$ nanocomposite films becomes thinner with increasing the initial zinc ion loadings. As the $\mathrm{ZnO}$ nanoparticles grow larger or aggregate together 


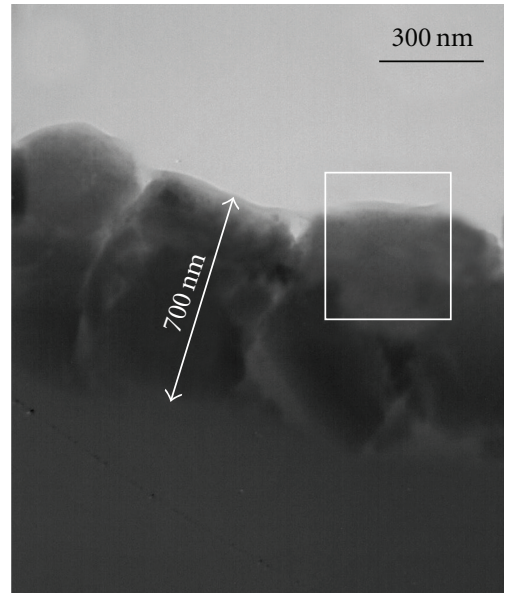

(a)

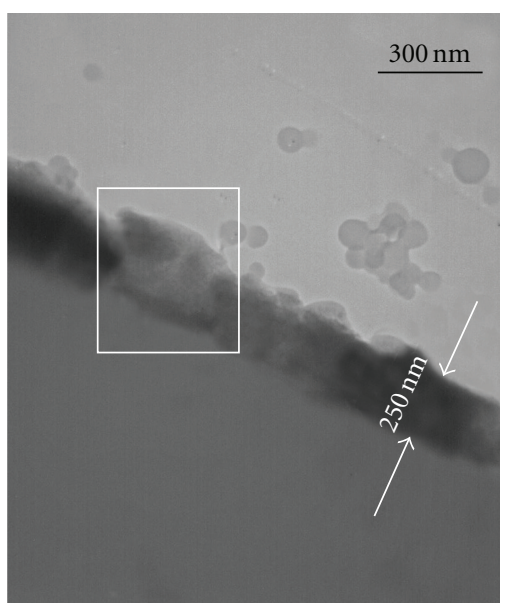

(d)

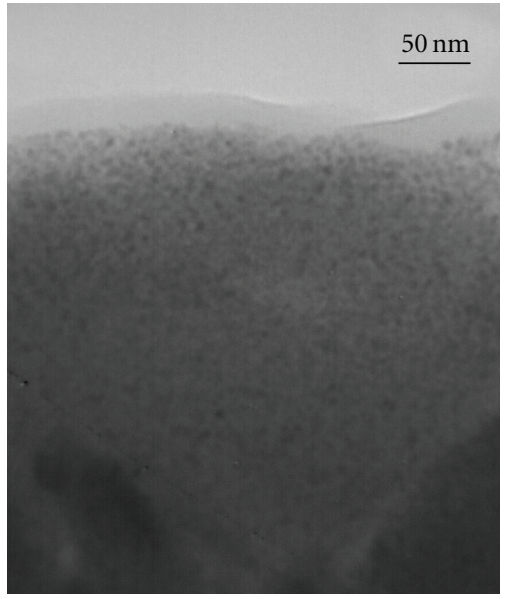

(b)

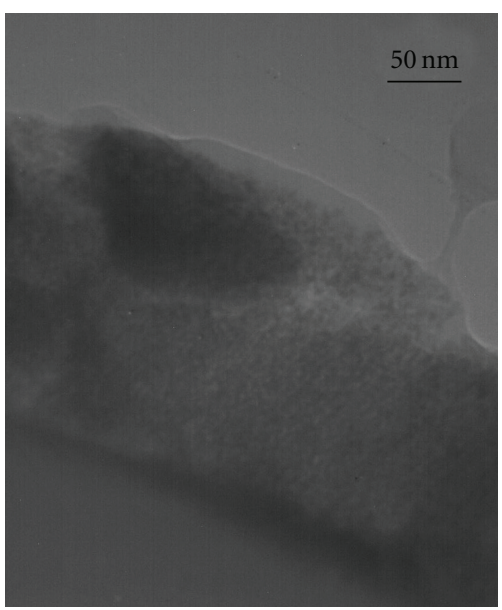

(e)

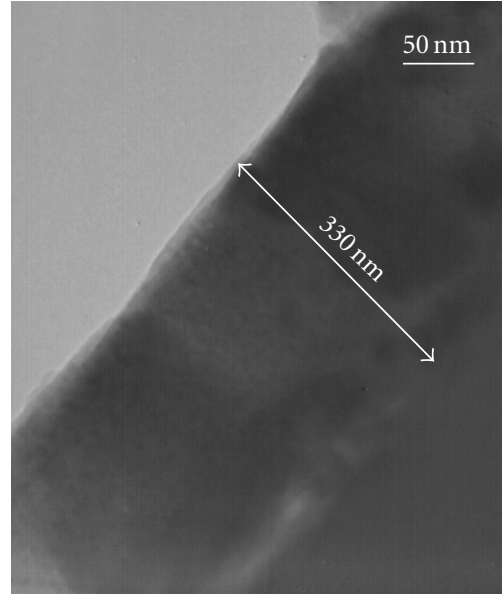

(c)

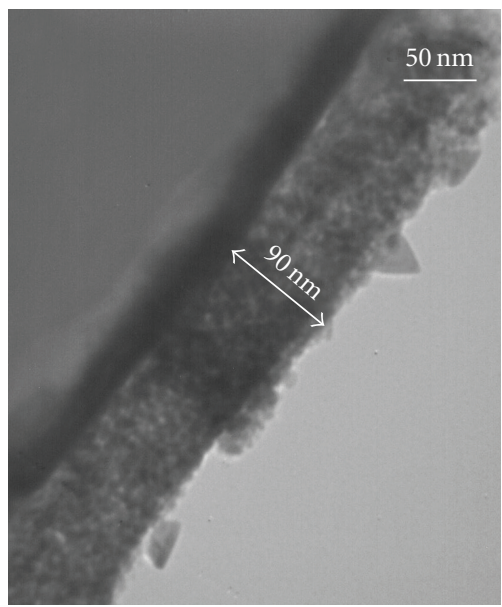

(f)

FIGURE 5: TEM images of the PI/ZnO films obtained at $350^{\circ} \mathrm{C} / 7 \mathrm{~h}$. Zinc ion loadings before thermal treatment were (a) and (b) 465 , (c) 611 , (d) and (e) 702 , and (f) $803 \mathrm{nmol} / \mathrm{cm}^{2}$, respectively.

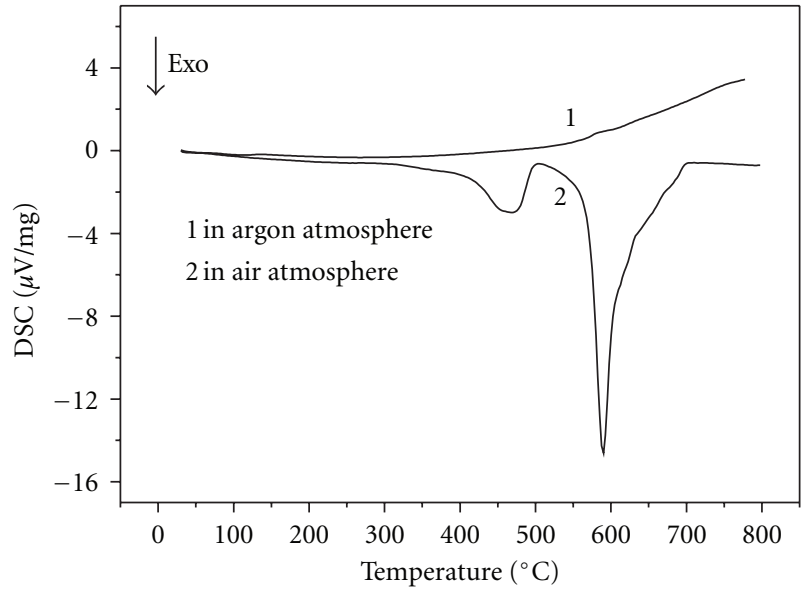

(a)

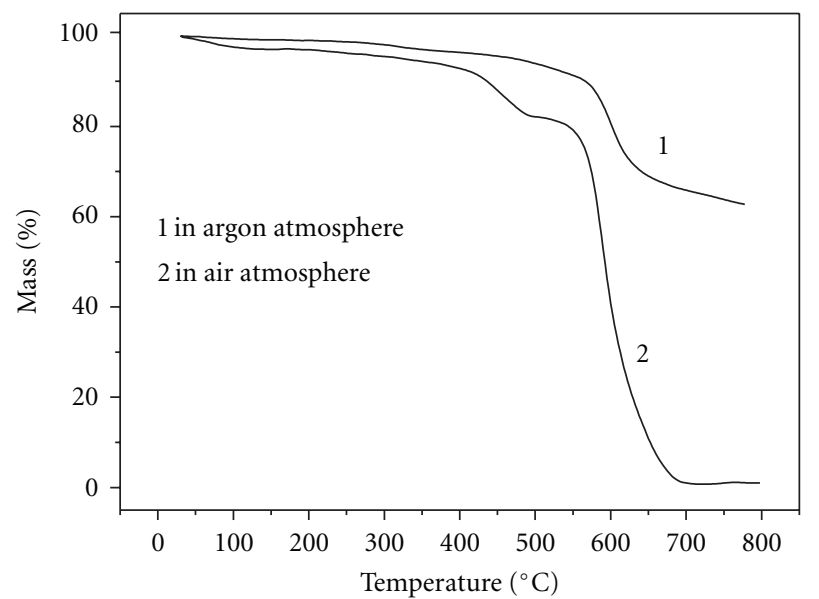

(b)

FIgURE 6: (a) DSC and (b) TGA curves of the $\mathrm{Zn}^{2+}$-doped $\left(3960 \mathrm{nmol} / \mathrm{cm}^{2}\right)$ PI precursor film obtained in air and argon atmosphere, respectively. 
with surrounding nanoparticles, their catalytic effect will be greatly weakened. Therefore, the oxidative degradation of PI catalyzed by the newly formed $\mathrm{ZnO}$ nanoparticles only occurred in a limited temperature range as can be observed in Figures 6(a)-1 and 6(b)-1. When the temperature reached over $520^{\circ} \mathrm{C}$, significant weight loss was progressed up to $700^{\circ} \mathrm{C}$ due to the oxidative degradation of PI matrix.

3.3. PL Characteristics of ZnO-Modified PI Films. Figure 7 shows the room temperature PL spectra for the bare PI film and the PI film with $3960 \mathrm{nmol} / \mathrm{cm}^{2}$ initial zinc ion loading after thermal treatment at $350^{\circ} \mathrm{C}$ for different hours. For the bare PI film, there was only one broad visible emission bond centered at $586 \mathrm{~nm}$, while the PL spectra for the zinc ion-doped PI films after thermal treatment at $350^{\circ} \mathrm{C}$ for $3 \mathrm{~h}$ and $5 \mathrm{~h}$ were much similar to that of the bare PI film. However, when the PI composite film was thermally treated at $350^{\circ} \mathrm{C}$ for $7 \mathrm{~h}$, an ultraviolet (UV) emission peak emerged at $367 \mathrm{~nm}$. According to the literature, the UV emission peak at $367 \mathrm{~nm}$ was originated from the excitonic recombination corresponding to the near band edge (NBE) emission of wide band gap $\mathrm{ZnO}$ [2-5]. This indicates that thermal treatment of the composite films should be carried out for at least $7 \mathrm{~h}$ at $350^{\circ} \mathrm{C}$ in order to obtain effective PL properties. With increasing thermal treatment time at $350^{\circ} \mathrm{C}$, the visible emission peak gradually shifted to lower wavelength. It was known that $\mathrm{ZnO}$ nanoparticles usually exhibit two emission peaks when excited with UV light. One is exhibited at around $370 \mathrm{~nm}$, and the other is near $525 \mathrm{~nm}$ (the so-called green luminescence band) whose mechanism seems much more complicated [3]. The blue shifting of the visible emission peaks by long-time thermal treatment may be due to the synergy of $\mathrm{ZnO}$ particles and PI matrix. Besides, another emission peak at $672 \mathrm{~nm}$ appeared in the PL spectrum of the $\mathrm{PI} / \mathrm{ZnO}$ composite film obtained at $350^{\circ} \mathrm{C} / 7 \mathrm{~h}$. The emission at $\sim 672 \mathrm{~nm}$ is frequently observed in the $\mathrm{ZnO}$ materials which exhibits oxygen-rich nature, that is, the stoichiometric ratio $\mathrm{Zn}: \mathrm{O}$ is $(1-x): 1(x>0)[5,37,38]$. It is suggested that the emission peak at $672 \mathrm{~nm}$ observed in the PI/ZnO nanocomposite film might also be the consequence of excess oxygen as the film was thermally treated in air atmosphere. The PL spectra of all the $\mathrm{PI} / \mathrm{ZnO}$ composite films with $465 \sim 803 \mathrm{nmol} / \mathrm{cm}^{2}$ initial zinc ion loadings obtained at $350^{\circ} \mathrm{C} / 7 \mathrm{~h}$ possess a weak UV emission peak and a broad and strong visible emission peak centered at $374 \mathrm{~nm}$ and $608 \mathrm{~nm}$, respectively. Figure 8 shows the PL spectra in wavelength of $330 \sim 450 \mathrm{~nm}$ of the PI/ZnO nanocomposite films with 611, 803 , and $3960 \mathrm{nmol} / \mathrm{cm}^{2}$ initial zinc ion loadings. An increase in peak density with increasing initial zinc ion loadings was observed. It was also found that the UV emission of the $\mathrm{PI} / \mathrm{ZnO}$ nanocomposite film has a slight blue shift. This blue shift is probably caused by the size change of $\mathrm{ZnO}$ nanoparticles [39] and the high concentration aggregates of $\mathrm{ZnO}$ nanoparticles in PI film surface layers [21] as shown in Figure 5(f).

3.4. Thermal Properties of the Composite Films. The thermal properties of the $\mathrm{PI} / \mathrm{ZnO}$ nanocomposite films were assessed

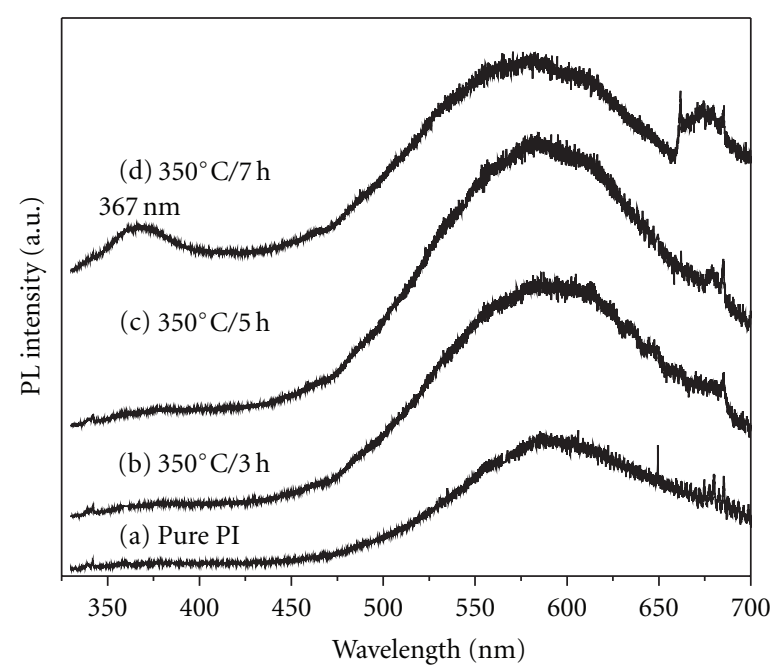

Figure 7: Room temperature PL spectra of (a) the bare PI film and the $\mathrm{PI} / \mathrm{ZnO}$ composite films after thermal treatment at $350^{\circ} \mathrm{C}$ for (b) 3 , (c) 5 , and (d) $7 \mathrm{~h}$. The zinc ion loading before thermal treatment is $3960 \mathrm{nmol} / \mathrm{cm}^{2}$.

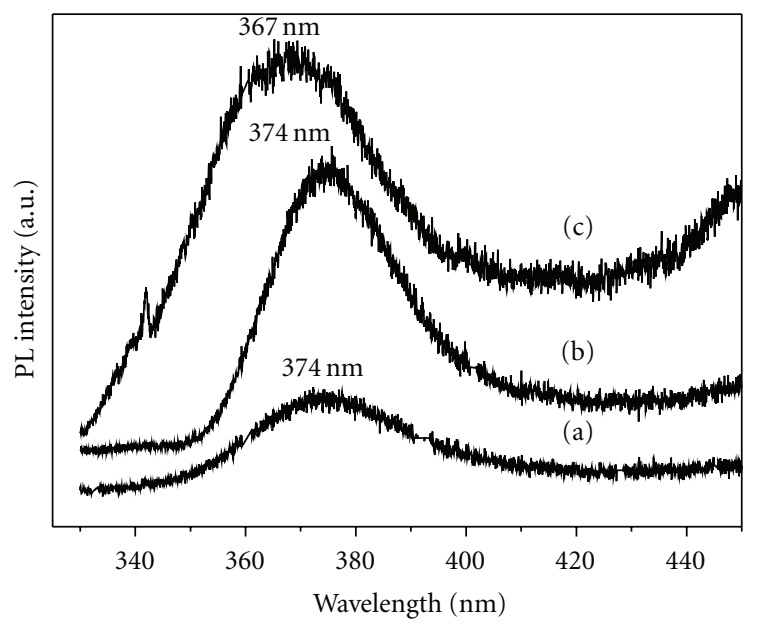

FIGURE 8: Room temperature PL spectra of PI/ZnO composite films obtained at $350^{\circ} \mathrm{C} / 7 \mathrm{~h}$. The initial $\mathrm{Zn}^{2+}$ loadings are (a) 611, (b) 803 , and (c) $3960 \mathrm{nmol} / \mathrm{cm}^{2}$.

by TG-DSC, and the results are shown in Figure 9. The TGA curves indicate that the presence of $\mathrm{ZnO}$ nanoparticles in surface layers has little effect on the thermal properties of the final nanocomposite films, and even the thermal properties of the $\mathrm{PI} / \mathrm{ZnO}$ composite films are superior to those of the bare PI film. The exothermic peaks in the temperature range of $520 \sim 680^{\circ} \mathrm{C}$ of the $\mathrm{PI} / \mathrm{ZnO}$ nanocomposite films were much stronger than that of PI film. This is suggested to arise from the further aggregation of $\mathrm{ZnO}$ nanoparticles during oxidative degradation of PI films. Another small exothermic peak emerged in the DSC curve of the PI/ZnO films (3960 $\mathrm{nmol} / \mathrm{cm}^{2}$ zinc ion loading) in the temperature range of $420 \sim 470^{\circ} \mathrm{C}$. It is probable that a little amount of $\mathrm{ZnO}$ nanoparticles did not grow to larger particles during thermal treatment because of its high concentration of initial 


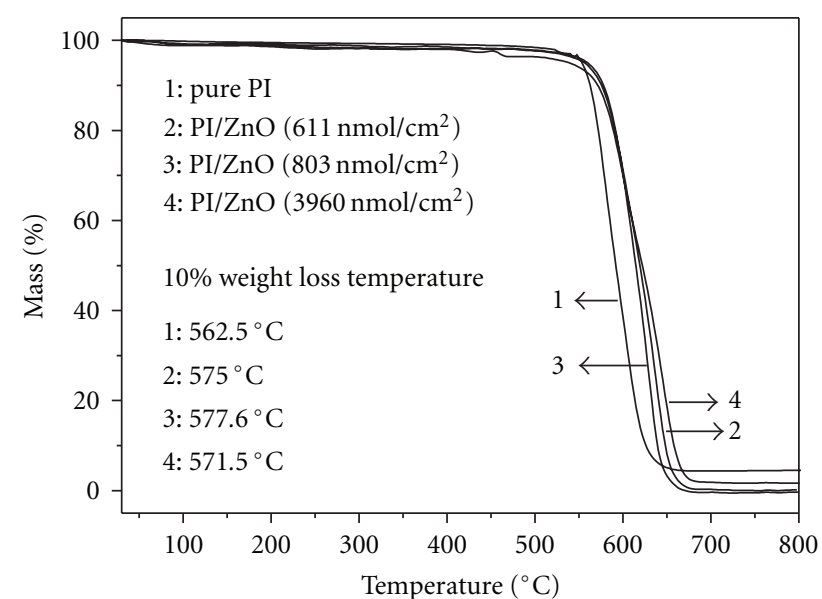

(a)

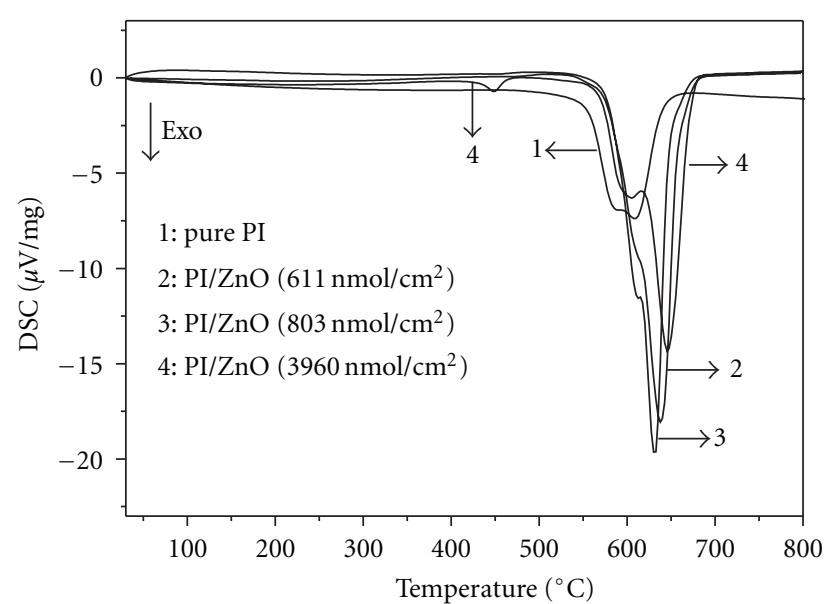

(b)

Figure 9: (a) TGA and (b) DSC curves of the bare PI film and the PI/ZnO composite films obtained at $350^{\circ} \mathrm{C} / 7 \mathrm{~h}$.

zinc ion loading. During elevating temperature in TGA-DSC measurement, these small $\mathrm{ZnO}$ nanoparticles may accelerate the oxidative decomposition of surrounding carbon. However, the weight loss resulted from this exothermic effect is negligible as can be seen in Figure 9(b).

\section{Conclusions}

Different content of $\mathrm{ZnO}$ nanoparticles embedded $\mathrm{PI} / \mathrm{ZnO}$ films can be prepared by $\mathrm{KOH}$ hydrolyzation, ion exchange in aqueous $\mathrm{Zn}\left(\mathrm{NO}_{3}\right)_{2}$ solution, and thermal treatment of the zinc ion-doped PI films in air atmosphere. The zinc ion loadings in the surface-treated layer of PI films after same alkali treatment were enhanced with increasing the concentration of aqueous $\mathrm{Zn}\left(\mathrm{NO}_{3}\right)_{2}$ solution while maintaining ion-exchange time at $5 \mathrm{~min}$. However, satisfying ion exchange can be performed by extending alkali treatment and ion-exchange time. $\mathrm{ZnO}$ nanoparticles of about 10 $15 \mathrm{~nm}$ were homogenously dispersed in the PI film surface layers. The formation and growth of $\mathrm{ZnO}$ nanoparticles during thermal treatment was a relative slower process, which was accompanied by the oxidative decomposition of surrounding PI matrix in the modified layer catalyzed by the $\mathrm{ZnO}$ nanoparticles. The room temperature PL spectrum of the $\mathrm{PI} / \mathrm{ZnO}$ composite films showed only one broad visible band when they were thermally treated at $350^{\circ} \mathrm{C}$ for less than $7 \mathrm{~h}$, while showed a weak UV emission band and a broad and strong visible band when the film was thermal-treated at $350^{\circ} \mathrm{C}$ for more than $7 \mathrm{~h}$. The intensity of the UV emission peak of the $\mathrm{PI} / \mathrm{ZnO}$ composite films obtained at $350^{\circ} \mathrm{C} / 7 \mathrm{~h}$ increased with enhancing the concentration of $\mathrm{ZnO}$. The composite film kept the excellent thermal properties of the host PI film.

\section{Acknowledgments}

The authors gratefully acknowledge the financial support from the National Natural Science Foundation of China
(NSFC, Project 50973006), the program for the National High Technology Research and Development of China (863 Program, Project no. 2007AA03Z537), and the Program for Changjiang Scholars and Innovative Research Team in the university (PCSIRT, IRT0706).

\section{References}

[1] Q. L. Huang, M. Wang, H. X. Zhong, X. T. Chen, Z. L. Xue, and X. Z. You, "Netlike nanostructures of $\mathrm{Zn}(\mathrm{OH}) \mathrm{F}$ and $\mathrm{ZnO}$ : synthesis, characterization, and properties," Crystal Growth and Design, vol. 8, no. 4, pp. 1412-1417, 2008.

[2] Y. Tong, Y. Liu, C. Shao et al., "Growth and optical properties of faceted hexagonal $\mathrm{ZnO}$ nanotubes," Journal of Physical Chemistry B, vol. 110, no. 30, pp. 14714-14718, 2006.

[3] Y. Masuda, M. Yamagishi, W. S. Seo, and K. Koumoto, "Photoluminescence from $\mathrm{ZnO}$ nanoparticles embedded in an amorphous matrix," Crystal Growth and Design, vol. 8, no. 5, pp. 1503-1508, 2008.

[4] Z. Y. Jiang, T. Xu, Z. X. Xie et al., "Molten salt route toward the growth of $\mathrm{ZnO}$ nanowires in unusual growth directions," Journal of Physical Chemistry B, vol. 109, no. 49, pp. 2326923273, 2005.

[5] S. Li, Z. W. Li, Y. Y. Tay, J. Armellin, and W. Gao, "Growth mechanism and photonic behaviours of nanoporous $\mathrm{ZnO}$ microcheerios," Crystal Growth and Design, vol. 8, no. 5, pp. 1623-1627, 2008.

[6] L. Guo, S. Yang, C. Yang et al., "Synthesis and characterization of poly(vinylpyrrolidone)-modified zinc oxide nanoparticles," Chemistry of Materials, vol. 12, no. 8, pp. 2268-2274, 2000.

[7] E. Tang, G. Cheng, X. Pang, X. Ma, and F. Xing, "Synthesis of nano- $\mathrm{ZnO} /$ poly(methyl methacrylate) composite microsphere through emulsion polymerization and its UV-shielding property," Colloid and Polymer Science, vol. 284, no. 4, pp. 422$428,2006$.

[8] C. H. Hung and W. T. Whang, "Effect of surface stabilization of nanoparticles on luminescent characteristics in $\mathrm{ZnO} /$ poly(hydroxyethyl methacrylate) nanohybrid films," Journal of Materials Chemistry, vol. 15, no. 2, pp. 267-274, 2005.

[9] M. Abdullah, T. Morimoto, and K. Okuyama, "Generating blue and red luminescence from $\mathrm{ZnO} /$ poly(ethylene glycol) 
nanocomposites prepared using an in-situ method," Advanced Functional Materials, vol. 13, no. 10, pp. 800-804, 2003.

[10] J. I. Hong, L. S. Schadler, R. W. Siegel, and E. Mårtensson, "Rescaled electrical properties of $\mathrm{ZnO} /$ low density polyethylene nanocomposites," Applied Physics Letters, vol. 82, no. 12, pp. 1956-1958, 2003.

[11] J. Lee, D. Bhattacharyya, A. J. Easteal, and J. B. Metson, "Properties of nano- $\mathrm{ZnO} / \mathrm{poly}$ (vinyl alcohol)/poly(ethylene oxide) composite thin films," Current Applied Physics, vol. 8, no. 1, pp. 42-47, 2008.

[12] J. Zheng, R. W. Siegel, and C. G. Toney, "Polymer crystalline structure and morphology changes in nylon-6/ZnO nanocomposites," Journal of Polymer Science B, vol. 41, no. 10, pp. 1033 1050, 2003.

[13] J. Zheng, R. Ozisik, and R. W. Siegel, "Phase separation and mechanical responses of polyurethane nanocomposites," Polymer, vol. 47, no. 22, pp. 7786-7794, 2006.

[14] A. Kuoni, R. Holzherr, M. Boillat, and N. F. De Rooij, "Polyimide membrane with $\mathrm{ZnO}$ piezoelectric thin film pressure transducers as a differential pressure liquid flow sensor," Journal of Micromechanics and Microengineering, vol. 13, no. 4, pp. S103-S107, 2003.

[15] H. Y. Yang, S. P. Lau, S. F. Yu et al., "Field emission from zinc oxide nanoneedles on plastic substrates," Nanotechnology, vol. 16, no. 8, pp. 1300-1303, 2005.

[16] M. Matsumura and R. P. Camata, "Pulsed laser deposition and photoluminescence measurements of $\mathrm{ZnO}$ thin films on flexible polyimide substrates," Thin Solid Films, vol. 476, no. 2, pp. 317-321, 2005.

[17] H. Nishinara, T. Kawaharamura, and S. Fujita, "Lowtemperature growth of $\mathrm{ZnO}$ thin films by linear source ultrasonic spray chemical vapor deposition," Japanese Journal of Applied Physics, vol. 46, no. 10 A, pp. 6811-6813, 2007.

[18] C. T. Chiang, R. L. DeLeon, and J. F. Garvey, "Preparation of zinc oxide thin films by reactive pulsed arc molecular beam deposition," Journal of Physical Chemistry C, vol. 111, no. 48, pp. 17700-17704, 2007.

[19] K. Kitamura, T. Yatsui, and M. Ohtsu, "Optical and structural properties of $\mathrm{ZnO}$ nanorods grown on polyimide films," Applied Physics Express, vol. 1, no. 8, Article ID 081202, 3 pages, 2008.

[20] S. C. Hsu, W. T. Whang, C. H. Hung, P. C. Chiang, and YI. N. Hsiao, "Effect of the polyimide structure and $\mathrm{ZnO}$ concentration on the morphology and characteristics of polyimide/ZnO nanohybrid films," Macromolecular Chemistry and Physics, vol. 206, no. 2, pp. 291-298, 2005.

[21] A. Somwangthanaroj, C. Phanthawonge, S. Ando, and W. Tanthapanichakoon, "Effect of the origin of $\mathrm{ZnO}$ nanoparticles dispersed in polyimide films on their photoluminescence and thermal stability," Journal of Applied Polymer Science, vol. 110, no. 4, pp. 1921-1928, 2008.

[22] E. K. Kim, J. H. Kim, H. K. Noh, and Y. H. Kim, "Electrical properties of $\mathrm{ZnO}$ nano-particles embedded in polyimide," Journal of Electronic Materials, vol. 35, no. 4, pp. 512-515, 2006.

[23] H. G. Roh, G. H. Kim, and Y. H. Kim, "Effect of curing conditions on the fabrication of $\mathrm{Zn}$-oxide nanoparticles dispersed in a polyimide film," High Performance Polymers, vol. 18, no. 5, pp. 739-747, 2006.

[24] Z. Wu, D. Wu, W. Yang, and R. Jin, "Preparation of highly reflective and conductive metallized polyimide films through surface modification: processing, morphology and properties," Journal of Materials Chemistry, vol. 16, no. 3, pp. 310316, 2006.
[25] S. Yang, D. Wu, S. Qi, G. Cui, R. Jin, and Z. Wu, "Fabrication of highly reflective and conductive double-surface-silvered layers embedded on polymeric films through all-wet process at room temperature," Journal of Physical Chemistry B, vol. 113, no. 29, pp. 9694-9701, 2009.

[26] S. Ikeda, K. Akamatsu, H. Nawafune, T. Nishino, and S. Deki, "Formation and growth of copper nanoparticles from ion-doped precursor polyimide layers," Journal of Physical Chemistry B, vol. 108, no. 40, pp. 15599-15607, 2004.

[27] K. Akamatsu, S. Ikeda, H. Nawafune, and S. Deki, "Surface modification-based synthesis and microstructural tuning of nanocomposite layers: monodispersed copper nanoparticles in polyimide resins," Chemistry of Materials, vol. 15, no. 13, pp. 2488-2491, 2003.

[28] S. Ikeda, H. Yanagimoto, K. Akamatsu, and H. Nawafune, "Copper/pohimide heterojunctions: controlling interfacial structures through an additive-based, all-wet chemical process using ion-doped precursors," Advanced Functional Materials, vol. 17, no. 6, pp. 889-897, 2007.

[29] S. Mu, Z. Wu, Y. Wang, S. Qi, X. Yang, and D. Wu, "Formation and characterization of cobalt oxide layers on polyimide films via surface modification and ion-exchange technique," Thin Solid Films, vol. 518, no. 15, pp. 4175-4182, 2010.

[30] M. Quinten, "The color of finely dispersed nanoparticles," Applied Physics B, vol. 73, no. 4, pp. 317-326, 2001.

[31] J. C. Hulteen, C. J. Patrissi, D. L. Miner, E. R. Crosthwait, E. B. Oberhauser, and C. R. Martin, "Changes in the shape and optical properties of gold nanoparticles contained within alumina membranes due to low-Temperature annealing," Journal of Physical Chemistry B, vol. 101, no. 39, pp. 77277731, 1997.

[32] S. Mu, D. Wu, Y. Wang, Z. Wu, X. Yang, and W. Yang, "Fabrication of nickel oxide nanocomposite layer on a flexible polyimide substrate via ion exchange technique," ACS Applied Materials and Interfaces, vol. 2, no. 1, pp. 111-118, 2010.

[33] M. J. Turk, A. S. Ansari, W. B. Alston, G. S. Gahn, A. A. Frimer, and D. A. Scheiman, "Evaluation of the thermal oxidative stability of polyimides via TGA techniques," Journal of Polymer Science A, vol. 37, no. 21, pp. 3943-3956, 1999.

[34] W. Xie, W. P. Pan, and K. C. Chuang, "Thermal degradation study of polymerization of monomeric reactants (PMR) polymides," Journal of Thermal Analysis and Calorimetry, vol. 64, no. 2, pp. 477-485, 2001.

[35] J. J. Bergmeister, J. D. Rancourt, and L. T. Taylor, "Synthesis and characterization of magnetic iron-modified polyimide films," Chemistry of Materials, vol. 2, no. 6, pp. 640-641, 1990.

[36] C. Girardeaux, E. Druet, P. Demoncy, and M. Delamar, "The polyimide (PMDA/ODA)-titanium interface. Part 1. Untreated PMDA/ODA: an XPS, AES, AFM and Raman study," Journal of Electron Spectroscopy and Related Phenomena, vol. 70, no. 1, pp. 11-21, 1994.

[37] Z. Fan, P. C. Chang, J. G. Lu et al., "Photoluminescence and polarized photodetection of single $\mathrm{ZnO}$ nanowires," Applied Physics Letters, vol. 85, no. 25, pp. 6128-6130, 2004.

[38] A. El Hichou, M. Addou, J. Ebothé, and M. Troyon, "Influence of deposition temperature ( $\mathrm{T}$ ), air flow rate (f) and precursors on cathodoluminescence properties of $\mathrm{ZnO}$ thin films prepared by spray pyrolysis," Journal of Luminescence, vol. 113, no. 3-4, pp. 183-190, 2005.

[39] Y. Sun, G. M. Fuge, N. A. Fox, D. J. Riley, and M. N. R. Ashfold, "Synthesis of aligned arrays of ultrathin $\mathrm{ZnO}$ nanotubes on a Si wafer coated with a thin $\mathrm{ZnO}$ film," Advanced Materials, vol. 17, no. 20, pp. 2477-2481, 2005. 

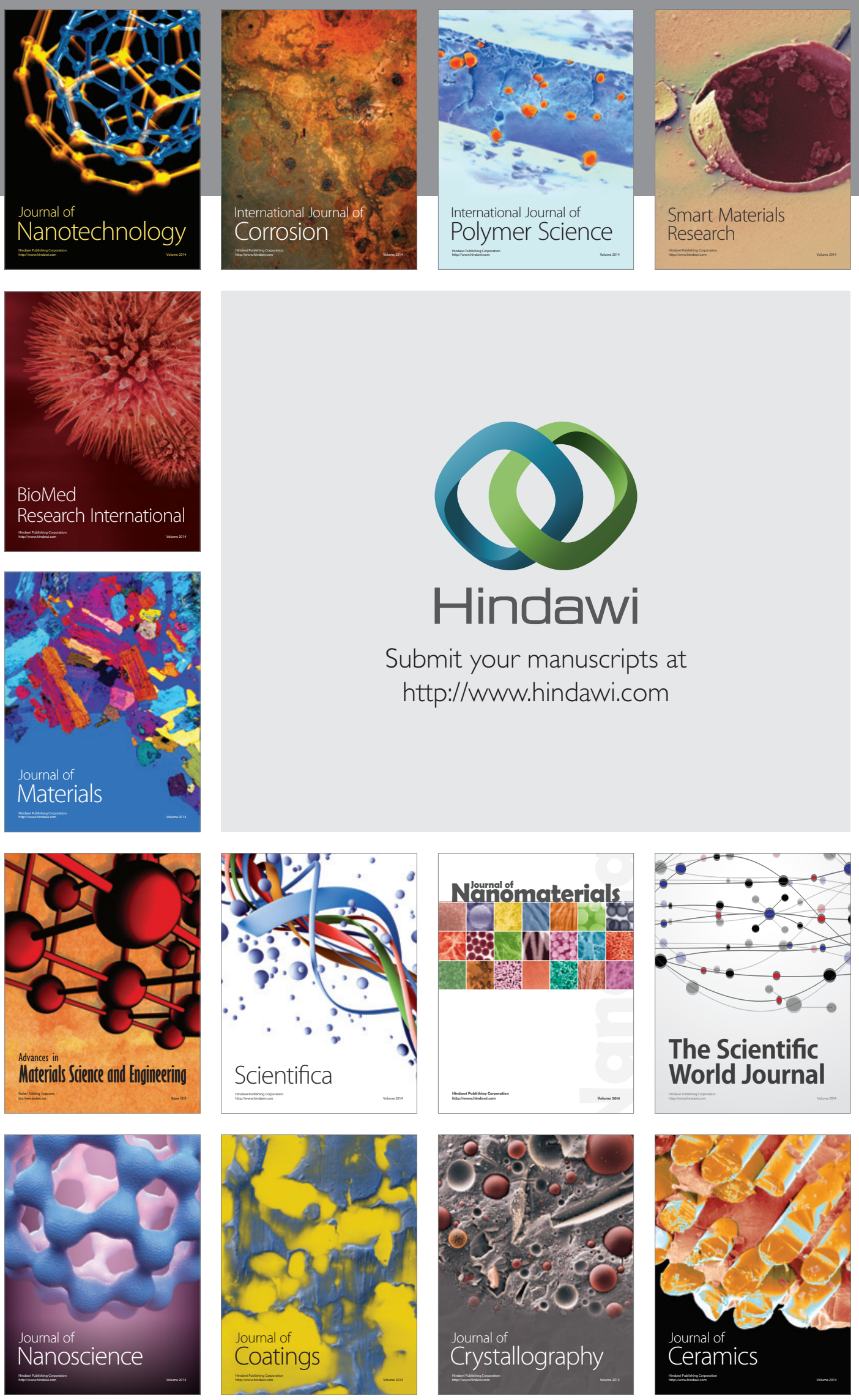

The Scientific World Journal

Submit your manuscripts at

http://www.hindawi.com

\section{World Journal}

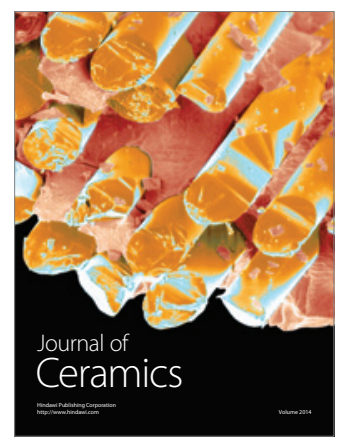

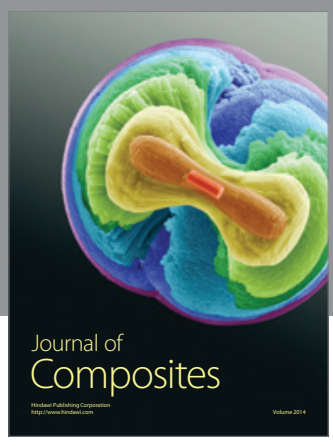
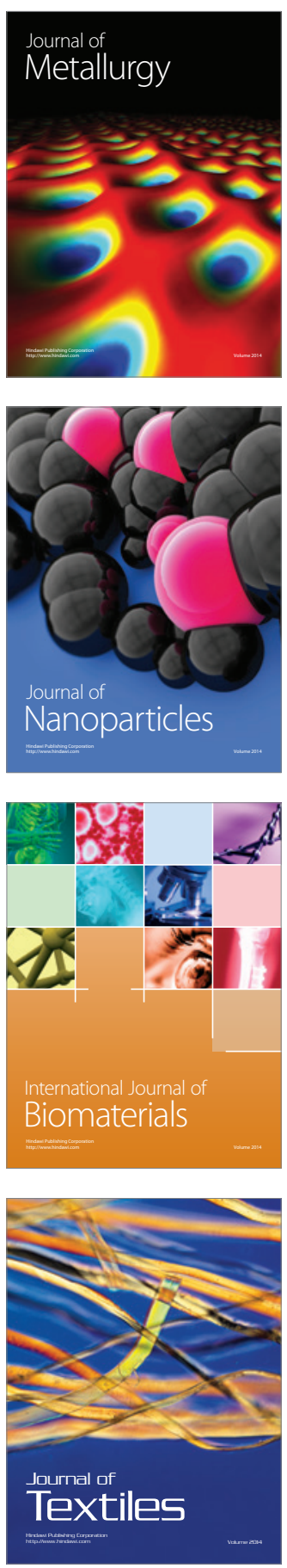